\title{
Species Identity and Initial Size Rather Than Neighborhood Interactions Influence Survival in a Response-Surface Examination of Competition
}

\section{Zhiqiang Shen ${ }^{\dagger}$, Yuanzhi $\mathrm{Li}^{\dagger}$, Zhiyi Chen, Nianxun Xi, Wenqi Luo, Qing He, Songling Liu, Wei Lin, Xianhui Zhu, Suqin Fang, Youshi Wang, Buhang Li and Chengjin Chu}

Department of Ecology, State Key Laboratory of Biocontrol, School of Life Sciences, Sun Yat-sen University, Guangzhou, China

OPEN ACCESS

Edited by:

Brian J. Palik,

United States Forest Service (USDA),

United States

Reviewed by:

Lu Min Vaario,

University of Helsinki, Finland

Long Yang,

Guangzhou Institute of Geography,

China

*Correspondence:

Chengjin Chu

chuchiin@mail.sysu.edu.cn

${ }^{\dagger}$ These authors have contributed equally to this work

Specialty section:

This article was submitted to Functional Plant Ecology,

a section of the journal

Frontiers in Plant Science

Received: 03 April 2020

Accepted: 24 July 2020

Published: 12 August 2020

Citation:

Shen Z, Li Y, Chen Z, Xi N, Luo W, He Q, Liu S, Lin W, Zhu X, Fang S,

Wang Y, Li B and Chu C (2020) Species Identity and Initial Size Rather

Than Neighborhood Interactions Influence Survival in a ResponseSurface Examination of Competition.

Front. Plant Sci. 11:1212. doi: 10.3389/fpls.2020.01212
To measure intraspecific and interspecific interaction coefficients among tree species is the key to explore the underlying mechanisms for species coexistence and biodiversity maintenance in forests. Through the response surface experimental design, we established a long-term field experiment by planting 27,300 seedlings of four tree species (Erythrophleum fordii, Pinus massoniana, Castanopsis fissa, and Castanopsis carlesii) in 504 plots in different species combinations (six pairwise combinations of four species), abundance proportions (five abundance proportions of two species, i.e. A: B = $1: 0,3: 1,1: 1,1: 3,0: 1)$, and stand densities $(25,36,64$, and 100 seedlings per plot). In this initial report, we aimed to quantify the relative importance of biotic and abiotic factors on seedling survival at the early stage of growth, which is a critical period for seedling establishment. We found that plot-level seedling survival rate was determined by species combination and their abundance proportion rather than stand density. At the individual level, individual survival probability was mainly explained by species identity, initial seedling size, and soil conditions rather than neighborhood competition. Our study highlights that the seedling intrinsic properties may be the key factors in determining seedling survival rate, while neighborhood effects were not yet prominent at the seedling life stage.

Keywords: abundance proportion, density, initial seedling size, negative density dependence, response surface design, seedling survival, soil properties, species combination

\section{INTRODUCTION}

Forests are one of the most important ecosystems in maintaining global biodiversity and consequently determine ecosystem functioning and services (Lang et al., 2012; Wang et al., 2012). The tree seedling stage is the period when survival and growth of individuals are most vulnerable to the change of surrounding biotic and abiotic factors. Exploring seedling survival and regeneration is crucial for understanding species coexistence and community dynamics (Kelly and Bowler, 2002; Lutz and Halpern, 2006), and management of forests (Muller-Landau et al., 2008; Liu S. et al., 2016). 
The tree seedling survival is known to be affected by its own intrinsic properties (e.g. its species identity and size, Wang et al., 2012) and its local conditions including biotic (e.g. neighbors, Comita and Hubbell, 2009) and abiotic factors (e.g. soil properties, Bai et al., 2012; Pu et al., 2017). A large body of research has demonstrated that seedling survival in natural communities was significantly influenced by species identity and initial size (Muller-Landau et al., 2008; Wang et al., 2012; Kabrick et al., 2015). For instance, Wang et al. (2012) found that seedling survival increased with its initial size. The larger seedlings can acquire reserves to withstand environmental stress and have an advantage over smaller seedlings in competition for light (Uriarte et al., 2004; Thorpe et al., 2010). Furthermore, different species compositions may result in different results, which indicates that the species identity of both target and neighboring saplings could influence sapling growth and survival (Lang et al., 2012; Yang et al., 2017). Besides the intrinsic properties of tree species, many studies have found that focal seedling survival was also strongly influenced by neighborhood individuals, including the number, diversity, size, and identity of neighbors (Comita and Hubbell, 2009; Chen et al., 2010; Zhu et al., 2015). Specifically, seedling survival was lower surrounded by neighbors of more conspecifics than heterospecifics ( $\mathrm{He}$ and Duncan, 2000; Comita and Hubbell, 2009; Castagneri et al., 2010; Pu et al., 2017), because of stronger intraspecific competition than interspecific competition for resources (Adler et al., 2018). In addition, tree seedling survival was affected by soil nutrients as well (Chen et al., 2010; Record et al., 2016). For example, seedlings were expected to survive better in soils with higher concentrations of total phosphorus and total nitrogen (Wang et al., 2012). Other soil properties including soil organic carbon and soil moisture also had a significant positive effect on seedling survival ( $\mathrm{Pu}$ et al., 2017), while topographic variables (e.g. elevation, slope, and aspect) did not (Wang et al., 2012).

To date, numerous tree seedling control experiments have been established worldwide with the original objective to test relationships between biodiversity and ecosystem functioning (Bruelheide et al., 2014; Van de Peer et al., 2016; Verheyen et al., 2016; Grossman et al., 2018). Some studies reported that species richness had no effects on individual seedling survival (Healy et al., 2008; Yang et al., 2013; Yang et al., 2017). These experiments have attempted to explore the survival of seedlings of various tree species and forest types and to test the effects of overall biodiversity on seedling performance. However, they failed to measure the relative importance of species composition, neighbor identity, and stand density on seedling survival due to the methodology limitation. Experimental studies that explicitly examined the relative importance of seedling intrinsic properties, its biotic and abiotic surroundings to individual seedling survival are necessary. Teasing apart the individual effects of those factors would substantially help us identify the key drivers of seedling survival.

The response surface experimental design, where both the density and proportion of the studied species are varying, allows predictions of the long-term ecological outcome of competition (Inouye, 2001; Damgaard, 2008). Therefore, it offers a unique opportunity to compare effects of species intrinsic properties, neighbor identity, individual density, and abiotic factors on focal plants (Inouye, 2001). Most previous studies have used this method to quantify the competitive interactions of plants in grasslands (Weigelt et al., 2007; Damgaard and Kjær, 2009; Damgaard and Fayolle, 2010) and of animals in terrestrial and aquatic ecosystems (e.g., invertebrates, Northfield et al., 2011; fishes, Forrester et al., 2006, and amphibians, Anderson and Whiteman, 2015). To date, few experiments have manipulated tree species, reflecting the logistical difficulties of conducting such complex experiments (Hart et al., 2012).

In this study, we grew four subtropical tree species in different species combinations and tested intra- and interspecific competition by manipulating abundance proportions and stand densities using the response surface experimental design. The overall aim of this experiment is to quantify the niche differences and average fitness differences (two key components of the modern coexistence theory) by measuring intraspecific and interspecific interaction coefficients among tree species, and to further explore the underlying mechanisms for species coexistence and biodiversity-ecosystem functioning relationships in forests (Chesson, 2000; Carroll et al., 2011; Chesson, 2018). In this initial report, we attempted to: (1) at the plot level, test the effects of species combination, abundance proportion, and stand density on the seedling survival rate, and (2) at the individual level, quantify the relative importance of seedling intrinsic properties (species identity and size), biotic (neighbors' size and density), and abiotic factors (soil properties) on seedling survival probability.

\section{MATERIALS AND METHODS}

\section{Study Site}

The experiment was established in January 2018 in the Heerkou, Fengkai County, Guangdong Province, China $\left(111^{\circ} 49^{\prime} \mathrm{E}, 23^{\circ} 30^{\prime} \mathrm{N}\right)$. This region has a subtropical humid monsoon climate, with the mean annual precipitation of $1744 \mathrm{~mm}$. About $79 \%$ of the annual rain falls between April and September, with a pronounced dry season from October to March. The mean maximum temperature is $19.6^{\circ} \mathrm{C}$, and monthly average temperature ranges from $10.6^{\circ} \mathrm{C}$ in January to $28.4^{\circ} \mathrm{C}$ in July (He et al., 2018; Wang et al., 2019).

\section{Experimental Design}

Our experiment included four tree species: Erythrophleum fordii (ERFO), Pinus massoniana (PIMA), Castanopsis fissa (CAFI), and Castanopsis carlesii (CACA), which co-occur naturally in the Dinghushan 20-ha forest dynamics plot, located in a nature reserve near to our experimental site (http://www.efloras.org/ flora_page.aspx?flora_id=620; Zhang et al., 2016). Two criteria were set initially in choosing the species: 1) species light strategies, with $P$. massoniana as the light-demanding species, and shadetolerant species of E. fordii, C. fissa, and C. carlesii; 2) mycorrhizal associations, with arbuscular mycorrhizal species of $E$. fordii, and ectomycorrhizal species of P. massoniana, C. fissa, and C. carlesii. Through these species settings, we plan to quantify the competitive coefficients among species with contrasting light strategies and 
explore the complementary effects due to mycorrhizal associations on the tree biodiversity-ecosystem functioning relationships. Six pairwise combinations of these four species emerged. Following the response surface experimental design, for each species combination (i.e. A and B), five abundance proportions of two species ( $\mathrm{A}: \mathrm{B}=1: 0,3: 1,1: 1,1: 3,0: 1$ ) were set at four different densities $(25,36,64$, and 100 seedlings per plot; Figure 1A). This would give us a total number of 120 plots (6 species combinations $\times 5$ abundance proportions $\times 4$ stand densities). However, we did not plant a single species $(\mathrm{A}: \mathrm{B}=1: 0$ or $0: 1)$ at the density of 100 seedlings per plot due to the limitation of the site size, which resulted in 108 plots. In addition, 24 more plots with only one species $(\mathrm{A}: \mathrm{B}=1: 0$ or $0: 1$ ) were redundant across the species combinations involving this species. Ultimately, 84 plots were planted in various combinations of species, abundance proportion and density. We set up six replications (blocks), with each block $(48 \mathrm{~m} \times 28 \mathrm{~m})$ consisting of 84 plots with the size of $4 \mathrm{~m} \times 4 \mathrm{~m}$ (Figure 1B). Overall, we planted $504(84 \times 6)$ plots with 27,300 seedlings. The tree seedlings were planted at the equal planting distance of $0.8,0.67,0.5$, and $0.4 \mathrm{~m}$ in the densities of 25 , 36,64 , and 100 seedlings per plot, respectively. The assignment of plots to treatments was completely randomized, as were the positions of individual tree seedlings within plots.

\section{Seedlings Planting and Management}

The experiment was conducted in an abandoned old field and fenced to exclude large mammalian herbivores in April 2018. Prior to the planting, vegetation in the field was completely removed with a rotary cultivator. Seedlings of the four species were bought from a commercial nursery, which were 1-2 years old ranging from $20 \mathrm{~cm}$ to $30 \mathrm{~cm}$ height. The seedlings were placed in a nearby temporary shade house to reduce the

A Response surface design

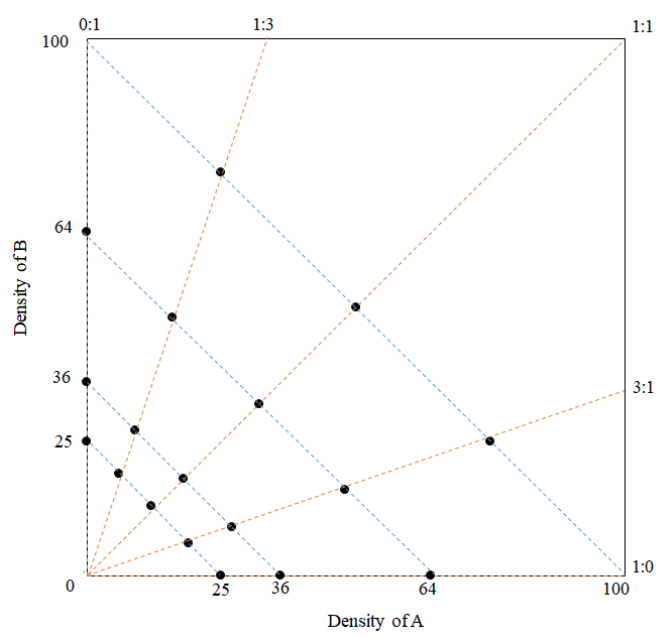

B Layout of the experiment following the response surface design
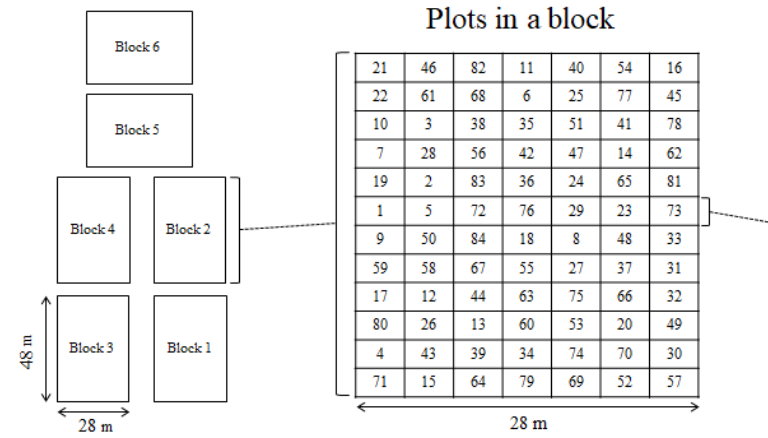

Saplings in a plot
\begin{tabular}{|c|c|c|c|c|c|c|c|}
\hline B & B & B & B & B & A & B & B \\
\hline A & B & B & B & A & A & A & B \\
\hline B & A & B & A & B & A & A & B \\
\hline B & A & A & B & B & B & B & B \\
\hline B & B & A & B & B & B & B & A \\
\hline B & B & B & B & B & B & A & B \\
\hline B & B & A & B & B & B & B & B \\
\hline A & B & B & B & B & B & B & B \\
\hline
\end{tabular}

FIGURE 1 | Design of the experiment. (A) For each species combination (A and $\mathbf{B}$ for the aim of presentation), 18 treatment combinations of abundance proportion and stand density were considered. (B) Each of the six blocks (48 m $\times 28 \mathrm{~m}$ ) contains 84 randomly distributed plots (4 $\mathrm{m} \times 4 \mathrm{~m})$. Each plot represents a treatment of species combination, abundance proportion and stand density. The tree seedlings were planted at the equal distance of $0.8,0.67,0.5$, and $0.4 \mathrm{~m}$, corresponding to the density of $25,36,64$, and 100 seedlings per plot, respectively. 
transpiration. Each seedling was planted in a hole $(30 \mathrm{~cm} \times$ $30 \mathrm{~cm} \times 20 \mathrm{~cm}$ ), and was watered every day for a week after planting to improve its survival probability. All seedlings were planted according to above planting scheme during April and May in 2018. Drainage channels were set around the blocks to prevent the seedlings from being drowned because of the intensive precipitation in summer. In October 2018, all dead seedlings during the 5 months were replanted. Each seedling was tagged with a unique number specifying its identity. The herbaceous vegetation was cleaned twice a year to reduce their effects on planted seedlings. All the cleanings were manual without using any herbicides.

\section{Survival Monitoring}

In December 2018, 27,029 seedlings were alive during the first survey of survival rate. For each seedling individual, the stem diameter at $5 \mathrm{~cm}$ above ground (hereafter ground diameter) were measured as the seedling initial size. Ground diameter was measured with a caliper to the nearest millimeter, and the position of the diameter measurement was permanently marked on the stem with white paint. The survival status of all seedlings was investigated in December 2019, living seedlings were coded as " 1 " and dead ones as “ 0 ". In total, 4,130 individual trees were dead during our second survival survey.

\section{Soil Properties}

In December 2018, five soil cores at a depth of $0-10 \mathrm{~cm}$ were sampled and mixed for each $4 \mathrm{~m} \times 4 \mathrm{~m}$ plot to estimate its average soil conditions. The soil samples were sent to the Institute of Botany of the Chinese Academy of Sciences for chemical analyses, including $\mathrm{pH}$, organic carbon $(\mathrm{C})$, total nitrogen (TN), available nitrogen (AN), total phosphorus (TP), and available phosphorus (AP), which were analyzed according to $\mathrm{Lu}$ (1999). We measured the bulk density (BD) and field capacity (FC) of each plot through the ring knife method (Sun Y. et al., 2017). To reduce collinearity of soil factors, principal components analyses (PCA) were conducted on these soil variables. The first two components (PC1 and PC2) accounted for $66.7 \%$ of the total variance in soil variables and were used in the subsequent analyses. The first principal component (PC1) was mainly associated with low $\mathrm{C}, \mathrm{TN}, \mathrm{AN}, \mathrm{TP}$, and $\mathrm{C} / \mathrm{N}$ ratio, and the second principal component (PC2) characterized by low FC, high $\mathrm{BD}$, and $\mathrm{pH}$ (Table S1).

\section{Statistical Analyses}

We first conducted ANOVAs to explore the effects of species combination, abundance proportion, stand density, and their interactions on survival rates of seedlings at the plot level.

To further explore what factors determined individual survival of these seedlings, we modeled individual survival using a logit link function with a generalized liner mixed model (GLMM) of the general form (a FULL model):

logit (seedling survival) $\sim$ seedling size $+\mathrm{PC} 1+\mathrm{PC} 2+$ Scon

+ Shet $+(1 \mid$ species $)+(1 \mid$ plot $)$
In this FULL model, seedling size is the initial ground diameter of seedlings. Scon and Shet are the sum of ground diameter of conspecific and heterospecific seedlings within $1 \mathrm{~m}$ radius of the focal seedling, respectively. PC1 and PC2 are the first two components of the total variance in soil variables. Species and plot were modeled as random effects. The variables used in the models were summarized in Table $\mathbf{S 2}$. All continuous explanatory variables were standardized to have zero mean and unit standard deviation prior to the statistical analyses (Bai et al., 2012).

To test the relative importance of seedling initial size, biotic, and abiotic variables, four candidate models were constructed: (1) a NULL model, including seedling ground diameter as only fixed effect; (2) a BIOTIC model, in which the fixed effects of seedling neighbors were added to the NULL model; (3) an ABIOTIC model, in which the fixed effects of soil properties were added to the NULL model; and (4) a FULL model, as described in the above equation, in which all fixed effects of variables were included in the NULL model. Models were compared using the Akaike's information criterion (AIC) to identify the best fit models, and ones with an AIC value $<2$ were considered to be equally valid (Burnham and Anderson, 2002). The variance explained by fixed factors was included in marginal $R^{2}\left(R_{\text {mar }}^{2}\right)$ and that by both fixed and random factors was in conditional $R^{2}\left(R_{\text {con }}^{2}\right)$ of the models (Nakagawa and Schielzeth, 2013).

To measure the partial effect of each variable on the odds of survival, we calculated odds ratios for each coefficient (the exponential of the estimate of each coefficient). Odds ratio $>1$ indicates a positive effect on survival, while ratio $<1$ indicates a negative effect. All data analyses were carried out with the software R version 3.5.3 (http://www.R-project.org).

\section{RESULTS}

\section{Plot-Level Survival}

A total of 27,029 seedlings were alive after the second planting in December 2018 and 22,899 seedlings survived to December 2019. The mean plot survival rate across species was $84.7 \%$, and the mean species survival rates were $98.7 \%, 98.9 \%, 48.0 \%$, and $94.4 \%$ for E. fordii, P. massoniana, C. fissa, and C. carlesii, respectively (Figure 2 ). The plot-level survival rates were significantly affected by species combination and abundance proportion as well as their interactions, but not affected by stand density or its interaction with species combination and abundance proportion (Table 1). Specifically, plots of species combination with higher proportion of $C$. fissa had lower survival rates (Figure 3).

\section{Individual-Level Survival}

The individual-level survival including all the four species was best modeled (lowest AIC) by the FULL model considering both biotic and abiotic factors. The fixed factors (seedling ground diameter, biotic neighbors, and soil properties) explained $9.4 \%$ of the variance (Table 2). Seedling size and heterospecific neighbors 


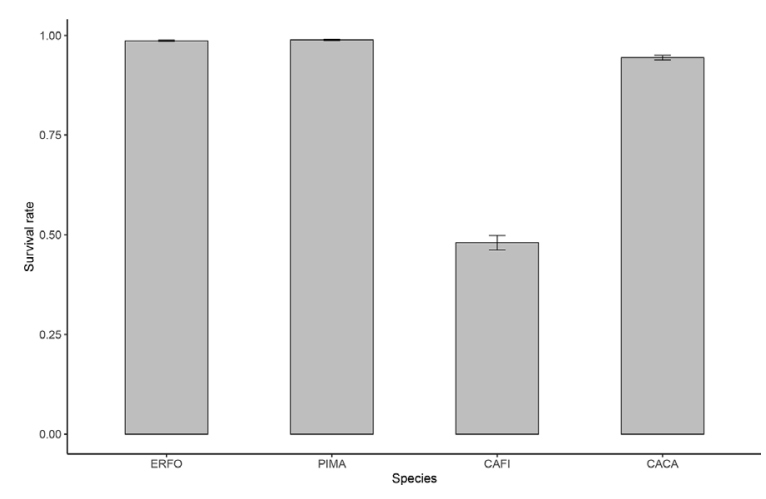

FIGURE 2 | Means and standard errors of seedling survival at the plot level for E. fordii (ERFO), P. massoniana (PIMA), C. fissa (CAFI), and C. carlesii (CACA).

had significantly positive effects, while PC1 of soils had negative effects on survival probability of focal seedlings indicated by the odds ratios (Figure 4A).

For each individual species, the best-fit model for $E$. fordii was the BIOTIC model, explaining $30.0 \%$ of the total variance by fixed factors (seedling ground diameter and biotic neighbors). The best-fit model for P. massoniana was the ABIOTIC model explaining $43.8 \%$ of the total variance by the fixed factors (soil properties). In contrast, the best-fit models for C. fissa and $C$. carlesii were the FULL models, with the fixed factors (seedling ground diameter, biotic neighbors, and soil properties) explaining $3.2 \%$ and $24.2 \%$ of the total variances (Table 2 ).

The effects of seedling size and abiotic and biotic factors on seedling survival varied among species. Seedling size had the most consistent effects on survival across all species: tree size had the strongest positive effect on survival of seedlings (odds ratio > 1.00, $P<0.001$; Figures 4A-E). There were no significant effects of neighbors on the survival of $E$. fordii seedlings. However, there was a significant positive effect of heterospecific neighboring seedlings on the survival of $C$. fissa (odds ratio $=1.23, P<0.001$; Figure 4D). Odds ratios for the parameters of the most likely model for seedlings also showed a significantly positive effect of neighboring conspecific seedlings on the survival of $C$. carlesii (odds ratio $=1.21, P=0.033$; Figure 4E). Soil PC1 showed a marginally negative effect on the survival of $C$. fissa and C. carlesii seedlings (odds ratio $=0.86, P=0.002$ for $C$. fissa; odds ratio = $0.78, P<0.001$ for C. carlesii; Figures 4D, E). Furthermore, soil

TABLE 1 | ANOVA results for the survival rates at the plot level.

\begin{tabular}{lccc}
\hline Variable Name & $\boldsymbol{d f}$ & $\boldsymbol{F}$ & $\boldsymbol{P}$ \\
\hline Combination & 5 & 134.068 & $<\mathbf{0 . 0 0 1}$ \\
Abundance proportion & 4 & 13.424 & $<\mathbf{0 . 0 0 1}$ \\
Stand density & 1 & 0.020 & 0.889 \\
Combination $\times$ abundance proportion & 20 & 27.108 & $<\mathbf{0 . 0 0 1}$ \\
Combination $\times$ stand density & 5 & 0.549 & 0.739 \\
Abundance proportion $\times$ stand density & 4 & 1.758 & 0.136 \\
Combination $\times$ abundance proportion $\times$ stand density & 20 & 0.594 & 0.918 \\
\hline
\end{tabular}

Significant values are highlighted in bold.
PC2 had a significantly negative effect on the seedling survival for $P$. massoniana and C. carlesii (odds ratio $=0.76, P=0.011$ for $P$. massoniana; odds ratio $=0.81, P=0.004$ for $C$. carlesii; Figures $4 B, E)$.

\section{DISCUSSION}

\section{Effects of Species Combination, Abundance Proportion, and Stand Density on Seedlings Survival at the Plot Level}

At the plot level, we found that species combination and abundance proportion played an important role in seedling survival in our experiment (Table 1). Previous studies showed that species composition affected the growth patterns and crown architecture of tree seedlings (Lang et al., 2012). This indicates that the neighbor tree identity is an important determinant of tree growth (von Oheimb et al., 2011). In our site, when growing together with E. fordii and P. massoniana, the survival rate of species pair combinations was usually high (Figure 3). Conversely, the plots with higher proportion of C. fissa generally had a lower survival rate (Figure 3). However, the density effects on seedling survival were weak in our study (Table 1), in contrast to previous findings (Johnson et al., 2014; Charles et al., 2018). One explanation might be that tree seedlings were too small and distant at the moment to detect significant interactions between them (Plath et al., 2011; von Oheimb et al., 2011). At this stage, these seedlings did not overlap in canopy competing for light and may not have developed extensive root systems competing for soil nutrients (Craine and Dybzinski, 2013; Yang et al., 2017).

\section{Species Identity and Initial Size Were Drivers of Seedlings Survival at the Individual Level}

Consistent with the plot-level survival rate, species identity had a significant impact on individual seedling survival probability (Figure 4), which was in line with previous studies in the biodiversity and ecosystem function (BEF) experiments with woody species (Nadrowski et al., 2010; Haase et al., 2015; Peng et al., 2017; Yang et al., 2017). Functional traits play a crucial role in tree seedling survival and growth (Kröber et al., 2015; Li et al., 2017). For instance, plant light-harvesting was significantly affected by branching frequency, leaf distribution, and leaf biomass (Niinemets, 2010; Li et al., 2017). Additionally, energy gain by increased light harvesting may be converted to plant growth and survival, and thus seedling survival and growth were related to species-specific traits (Poorter and Bongers, 2006; Kröber et al., 2015; Li et al., 2017). Wright et al. (2004) reported that the leaf economics spectrum (LES) reflected a mixture of direct and indirect causal relationships between traits. Leaf area plays a central role in leaf trait relationships and can predict tree growth (Osnas et al., 2013). Particularly in young plantations, large-leaved species need more nutrients to quickly increase a stand's leaf area index, but face greater mortality risk and are more vulnerable. In contrast, species with smaller leaves follow a more 

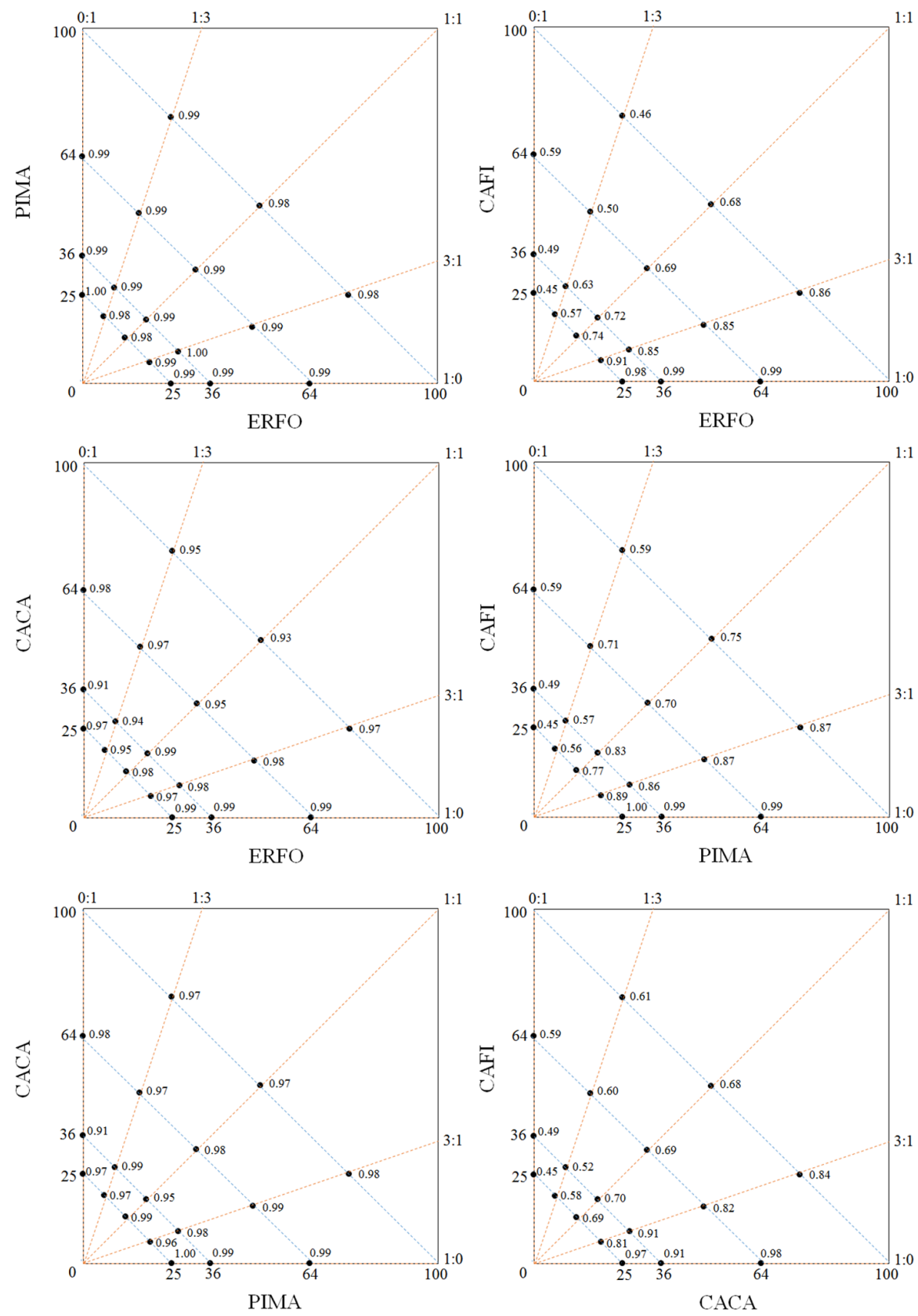

FIGURE 3 | Survival rates of the different treatments. E. fordii (ERFO), P. massoniana (PIMA), C. fissa (CAFI), and C. carlesii (CACA).

invariable investment strategy (Reich, 2014; Kröber et al., 2015). In our site, the survival rates of E. fordii, P. massoniana, and C. carlesii were above $90 \%$, while the survival rate of C. fissa was less than 50\% (Figure 2). This may be due to different growth strategies adopted by species. Specifically, the large leaves of C. fissa need more nutrients to achieve higher growth rates, but the root system did not get enough nutrients to support seedling survival. Another explanation for this might be that water would be a limited factor influencing tree survival at the early stage.
C. fissa has larger leaves, which may lead to a greater transpiration rate. In addition, C. fissa is a shade-tolerant species. Previous studies have shown that very shade-tolerant species lack alternative mechanisms to cope with excess light energy and are more likely to incur photoinhibitory damage to their photosynthetic apparatus (Rodríguez-Calcerrada et al., 2006). Therefore, C. fissa seedlings had a distinct photoinhibition which reduced carbon assimilation and growth under high radiation in open sites (Yang et al., 2010; Sun Z. et al., 2017). 
TABLE 2 | Effects of biotic and abiotic variables on survival rates of seedlings in December 2019.

\begin{tabular}{|c|c|c|c|c|c|c|c|c|c|c|c|c|}
\hline \multirow[t]{3}{*}{ Data subsets } & \multicolumn{12}{|c|}{ Candidate models } \\
\hline & \multicolumn{3}{|c|}{ NULL model } & \multicolumn{3}{|c|}{ BIOTIC model } & \multicolumn{3}{|c|}{ ABIOTIC model } & \multicolumn{3}{|c|}{ FULL model } \\
\hline & AIC & $R_{\text {mar }}^{2}(\%)$ & $R_{\text {con }}^{2}(\%)$ & AIC & $R_{\text {mar }}^{2}(\%)$ & $R_{\text {con }}^{2}(\%)$ & AIC & $R_{\text {mar }}^{2}(\%)$ & $R_{\text {con }}^{2}(\%)$ & AIC & $R_{\text {mar }}^{2}(\%)$ & $R_{\text {con }}^{2}(\%)$ \\
\hline Total & $12,022.9$ & 8.6 & 63.3 & $12,020.8$ & 8.8 & 63.6 & $12,007.4$ & 9.0 & 62.9 & $12,003.1$ & 9.4 & 63.3 \\
\hline \multicolumn{13}{|l|}{ Species } \\
\hline Erythrophleum fordii & 923.4 & 29.0 & 36.2 & 922.4 & 30.0 & 35.5 & 926.4 & 29.4 & 36.0 & 925.9 & 30.4 & 35.3 \\
\hline Pinus massoniana & 743.5 & 41.9 & 56.0 & 745.6 & 42.2 & 57.0 & 739.9 & 43.8 & 55.5 & 742.5 & 43.9 & 56.4 \\
\hline Castanopsis fissa & $7,649.0$ & 1.4 & 38.2 & 7638.2 & 2.3 & 39.2 & $7,745.5$ & 2.2 & 37.9 & $7,632.8$ & 3.2 & 38.8 \\
\hline Castanopsis carlesii & $2,500.5$ & 19.4 & 44.2 & 2501.0 & 20.1 & 44.3 & $2,474.3$ & 23.4 & 42.4 & $2,473.3$ & 24.2 & 42.4 \\
\hline
\end{tabular}

The best-fit models are highlighted in bold.

In agreement with the previous studies (Uriarte et al., 2004; Wang et al., 2012; Pu et al., 2017), we found a significantly positive relationship between initial size and seedling survival (Figures 4A-E). The possible reason is that the larger seedlings tend to maintain size advantage over time compared to smaller seedlings (Rose and Scott Ketchum, 2003) partly due to the ability to outgrow competing vegetation (South et al., 2005). In addition, large seedlings are usually in better positions in competition for light (Comita and Hubbell, 2009). However, previous studies also demonstrated that aboveground growth of seedlings did not always indicate the future performance. For instance, the root/shoot ratio has been reported to be directly related to seedling survival in several studies (Lloret et al., 1999; Vaario et al., 2009). The following measurement of root dynamics in our long-term experiment will help us identify the role of below-ground competition on demographic rates of trees.

\section{Effects of Soil Properties and Neighbors on Seedlings Survival at the Individual Level}

In our study, soil nutrients (soil organic carbon, soil total nitrogen, soil total phosphorus, and soil available nitrogen) were all positively associated with individual seedling survival of $C$. fissa and C. carlesii (Figures 4D, E; Wang et al., 2012; Liu S. et al., 2016; Pu et al., 2017; Yang et al., 2017). The root systems and stems of seedlings could not store more chemical elements at the early stage of the experiment for growth, resulting in more dependence on the available elements in the soil. Therefore, relatively fertile soil would be more beneficial to individual seedling survival of C. fissa and C. carlesii (Lin et al., 2012; Liu S. et al., 2016). However, the effects of soil nutrients on individual seedling survival rates were not significant for P. massoniana and E. fordii (Figures 4B, C). Previous studies reported that $P$. massoniana was effective at
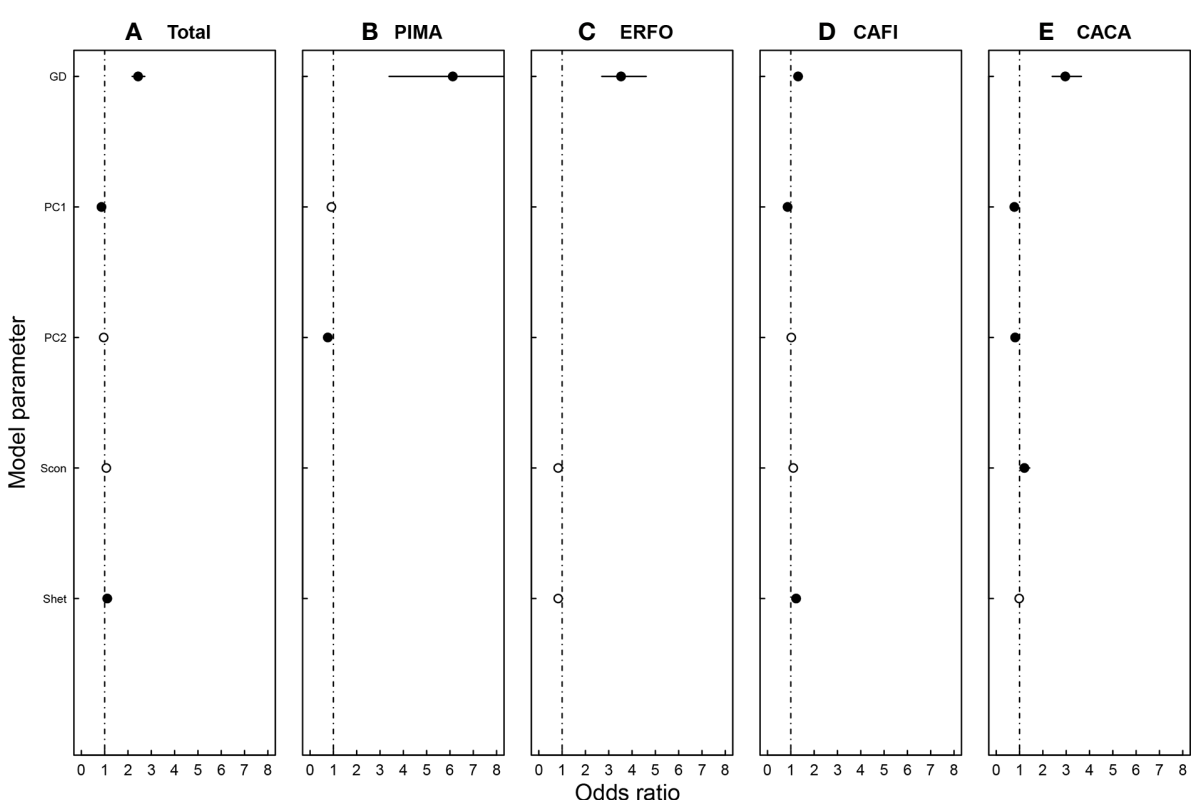

FIGURE 4 | Odds ratios of variables on seedling survival by the best-fit models for (A) all species, (B) P. massoniana (PIMA), (C) E. fordii (ERFO), (D) C. fissa (CAFI), and (E) C. carlesii (CACA). Circles show odds ratios for each parameter, with 95\% confidence limits indicated by horizontal lines. Black solid circles indicated significant effects $(P<0.05)$. Variable abbreviations: GD, ground diameter; Scon, sum of ground diameter for conspecific seedlings within $1 \mathrm{~m}$ radius; Shet, sum of ground diameter for heterospecific seedlings within $1 \mathrm{~m}$ radius. 
adapting to nutrient-poor soils (Liu J. et al., 2016), which could explain that soil nutrients did not have significant effects on $P$. massoniana seedling survival. Simultaneously, E. fordii is a nitrogen fixing tree species. Such characteristics could determine that this tree species has a special ability to improve tree growth and nutrition under nutrient limiting conditions and thus may not depend too much on soil nutrients (Chaer et al., 2011; Mortimer et al., 2013).

Previous studies found that negative density dependence (NDD) plays an important role in driving seedling survival (Comita and Hubbell, 2009; Bai et al., 2012; Pu et al., 2017; Charles et al., 2018). However, we found there was a weak association between conspecific neighbors and focal individual seedlings (Figures 4A, C, D). The reason was similar with that of no significant density effects on the plot-level survival rate. Conversely, we found that the focal seedling survival increased as the heterospecific individual seedlings increased (Figures 4A, D), indicating facilitative effects of heterospecific neighbors. Our findings are in agreement with previous studies that demonstrated the importance of heterospecific trees for survival of individual seedlings (Peters, 2003; Comita and Hubbell, 2009; Bai et al., 2012; $\mathrm{Pu}$ et al., 2017). These are consistent with the species herd protection hypothesis: heterospecific neighbors could depress the encounter probability of focal seedlings and its host-specific enemies and therefore have more benefit to the survival of focal seedlings (Wright, 2002; Peters, 2003; Comita and Hubbell, 2009). In summary, the NDD effect is not very strong at both the plot- and individual-level at the early stage of the experiment.

\section{CONCLUSIONS}

Our study presented comprehensive analyses on the relative importance of abiotic and biotic effects on seedling survival, and shed light on the driving factors for species coexistence and community assembly during forest succession. At the plot level, species combination and abundance proportion played an important role in seedling survival rate, while stand density showed little effect on seedling survival at the early stage of seedling planting experiment. At the individual level, species identity, seedling size, and soil properties were more important for seedling survival probability than neighborhood interactions. Although neighborhood interactions had a significant effect on seedling survival (Figures 4A, D, E), the effect of NDD was weak. With increasing size of trees, we predict that, as the competition between seedlings strengthens, the effect of the neighbors on the focal tree seedlings would become more pronounced.

\section{REFERENCES}

Adler, P. B., Smull, D., Beard, K. H., Choi, R. T., Furniss, T., Kulmatiski, A., et al. (2018). Competition and coexistence in plant communities: intraspecific competition is stronger than interspecific competition. Ecol. Lett. 21, 1319-1329. doi: 10.1111/ele.13098

Anderson, T. L., and Whiteman, H. H. (2015). Non-additive effects of intra- and interspecific competition between two larval salamanders. J. Anim. Ecol. 84, 765-772. doi: 10.1111/1365-2656.12335

\section{DATA AVAILABILITY STATEMENT}

The raw data supporting the conclusions of this article will be made available by the authors, without undue reservation.

\section{AUTHOR CONTRIBUTIONS}

CC initialized the project. ZS and CC designed the experiment. ZS, ZC, XZ, SL, QH, BL, and WL collected the data. ZS, ZC, and YL analyzed the data. ZS, YL, NX, WQL, SF, YW, and CC interpreted the results and wrote the manuscript. All authors contributed to the article and approved the submitted version.

\section{FUNDING}

This work was financially supported by the National Key R \& D Program of China (2017YFC0506101), and the National Natural Science Foundation of China (31925027, 31622014 and 31570426 to CC, and 31901106 to YL), the China Postdoctoral Science Foundation (2018M643295 to YL), and the Fundamental Research Funds for the Central Universities (20lgpy116).

\section{ACKNOWLEDGMENTS}

We are grateful to the MAPPING team for the assistance in establishing the experiment, especially to Bingwei Zhang, Yun Jiang, Weitao Wang, Junli Xiao, Wei Wei, Hanlun Liu, Yuan Jiang, Zongrui $\mathrm{Wu}$, and Dongxia Chen for coordinating the field work. We are indebted to Fuwen Lan, Zhanying Lin, Weiqiong Chen, and Liting Li for their great contribution as local helpers.

\section{SUPPLEMENTARY MATERIAL}

The Supplementary Material for this article can be found online at: https://www.frontiersin.org/articles/10.3389/fpls.2020.01212/ full\#supplementary-material

TABLE S1 | Variable loadings for principal component analyses on soil properties.

TABLE S2 | Parameters used in models of tree survival.

Bai, X., Queenborough, S. A., Wang, X., Zhang, J., Li, B., Yuan, Z., et al. (2012). Effects of local biotic neighbors and habitat heterogeneity on tree and shrub seedling survival in an old-growth temperate forest. Oecologia 170, 755-765. doi: 10.1007/s00442-012-2348-2

Bruelheide, H., Nadrowski, K., Assmann, T., Bauhus, J., Both, S., Buscot, F., et al. (2014). Designing forest biodiversity experiments: general considerations illustrated by a new large experiment in subtropical China. Methods Ecol. Evol. 5, 74-89. doi: 10.1111/2041-210X.12126 
Burnham, K. P., and Anderson, D. R. (2002). Model selection and multimodel inference: a practical information-theoretic approach (New York: Springer).

Carroll, I. T., Cardinale, B. J., and Nisbet, R. M. (2011). Niche and fitness differences relate the maintenance of diversity to ecosystem function. Ecology 92, 1157-1165. doi: 10.1890/10-0302.1

Castagneri, D., Lingua, E., Vacchiano, G., Nola, P., and Motta, R. (2010). Diachronic analysis of individual-tree mortality in a Norway spruce stand in the eastern Italian Alps. Ann. For. Sci. 67, 304. doi: 10.1051/forest/2009111

Chaer, G. M., Resende, A. S., Campello, E. F. C., de Faria, S. M., and Boddey, R. M. (2011). Nitrogen-fixing legume tree species for the reclamation of severely degraded lands in Brazil. Tree Physiol. 31, 139-149. doi: 10.1093/treephys/ tpq116

Charles, L. S., Dwyer, J. M., Smith, T. J., Connors, S., Marschner, P., and Mayfield, M. M. (2018). Species wood density and the location of planted seedlings drive early-stage seedling survival during tropical forest restoration. J. Appl. Ecol. 55, 1009-1018. doi: 10.1111/1365-2664.13031

Chen, L., Mi, X., Comita, L. S., Zhang, L., Ren, H., and Ma, K. (2010). Communitylevel consequences of density dependence and habitat association in a subtropical broad-leaved forest. Ecol. Lett. 13, 695-704. doi: 10.1111/j.1461-0248.2010.01468.x

Chesson, P. (2000). Mechanisms of maintenance of species diversity. Annu. Rev. Ecol. Syst. 31, 343-366. doi: 10.1146/annurev.ecolsys.31.1.343

Chesson, P. (2018). Updates on mechanisms of maintenance of species diversity. J. Ecol. 106, 1773-1794. doi: 10.1111/1365-2745.13035

Comita, L. S., and Hubbell, S. P. (2009). Local neighborhood and species' shade tolerance influence survival in a diverse seedling bank. Ecology 90, 328-334. doi: 10.1890/08-0451.1

Craine, J. M., and Dybzinski, R. (2013). Mechanisms of plant competition for nutrients, water and light. Funct. Ecol. 27, 833-840. doi: 10.1111/1365-2435.12081

Damgaard, C., and Fayolle, A. (2010). Measuring the importance of competition: a new formulation of the problem: Measuring the importance of competition. J. Ecol. 98, 1-6. doi: 10.1111/j.1365-2745.2009.01587.x

Damgaard, C., and Kjær, C. (2009). Competitive interactions and the effect of herbivory on Bt-Brassica napus, Brassica rapa and Lolium perenne. J. Appl. Ecol. 46, 1073-1079. doi: 10.1111/j.1365-2664.2009.01689.x

Damgaard, C. (2008). On the need for manipulating density in competition experiments. Funct. Ecol. 22, 931-933. doi: 10.1111/j.1365-2435.2008.01456.x

Forrester, G. E., Evans, B., Steele, M. A., and Vance, R. R. (2006). Assessing the magnitude of intra- and interspecific competition in two coral reef fishes. Oecologia 148, 632-640. doi: 10.1007/s00442-006-0397-0

Grossman, J. J., Vanhellemont, M., Barsoum, N., Bauhus, J., Bruelheide, H., Castagneyrol, B., et al. (2018). Synthesis and future research directions linking tree diversity to growth, survival, and damage in a global network of tree diversity experiments. Environ. Exp. Bot. 152, 68-89. doi: 10.1016/ j.envexpbot.2017.12.015

Haase, J., Castagneyrol, B., Cornelissen, J. H. C., Ghazoul, J., Kattge, J., Koricheva, J., et al. (2015). Contrasting effects of tree diversity on young tree growth and resistance to insect herbivores across three biodiversity experiments. Oikos 124, 1674-1685. doi: 10.1111/oik.02090

Hart, S. P., Burgin, J. R., and Marshall, D. J. (2012). Revisiting competition in a classic model system using formal links between theory and data. Ecology 93, 2015-2022. doi: 10.1890/11-2248.1

He, F., and Duncan, R. P. (2000). Density-dependent effects on tree survival in an old-growth Douglas fir forest. J. Ecol. 88, 676-688. doi: 10.1046/j.13652745.2000.00482.x

He, D., Chen, Y., Zhao, K., Cornelissen, J. H. C., and Chu, C. (2018). Intra- and interspecific trait variations reveal functional relationships between specific leaf area and soil niche within a subtropical forest. Ann. Bot. 121, 1173-1182. doi: $10.1093 / \mathrm{aob} / \mathrm{mcx} 222$

Healy, C., Gotelli, N. J., and Potvin, C. (2008). Partitioning the effects of biodiversity and environmental heterogeneity for productivity and mortality in a tropical tree plantation. J. Ecol. 96, 903-913. doi: 10.1111/j.1365-2745.2008.01419.x

Inouye, B. D. (2001). Response surface experimental designs for investigating interspecific competition. Ecology 82, 2696-2706. doi: 10.1890/0012-9658 (2001)082[2696:RSEDFI]2.0.CO;2

Johnson, D. J., Bourg, N. A., Howe, R., McShea, W. J., Wolf, A., and Clay, K. (2014). Conspecific negative density-dependent mortality and the structure of temperate forests. Ecology 95, 2493-2503. doi: 10.1890/13-2098.1
Kabrick, J. M., Knapp, B. O., Dey, D. C., and Larsen, D. R. (2015). Effect of initial seedling size, understory competition, and overstory density on the survival and growth of Pinus echinata seedlings underplanted in hardwood forests for restoration. New For. 46, 897-918. doi: 10.1007/s11056-015-9487-3

Kelly, C. K., and Bowler, M. G. (2002). Coexistence and relative abundance in forest trees. Nature 417, 437-440. doi: 10.1038/417437a

Kröber, W., Li, Y., Härdtle, W., Ma, K., Schmid, B., Schmidt, K., et al. (2015). Early subtropical forest growth is driven by community mean trait values and functional diversity rather than the abiotic environment. Ecol. Evol. 5, 35413556. doi: 10.1002/ece3.1604

Lang, A. C., Härdtle, W., Baruffol, M., Böhnke, M., Bruelheide, H., Schmid, B., et al. (2012). Mechanisms promoting tree species co-existence: Experimental evidence with saplings of subtropical forest ecosystems of China. J. Veg. Sci. 23, 837-846. doi: 10.1111/j.1654-1103.2012.01403.x

Li, Y., Kröber, W., Bruelheide, H., Härdtle, W., and von Oheimb, G. (2017). Crown and leaf traits as predictors of subtropical tree sapling growth rates. J. Plant Ecol. 10, 136-145. doi: 10.1093/jpe/rtw041

Lin, L., Comita, L. S., Zheng, Z., and Cao, M. (2012). Seasonal differentiation in density-dependent seedling survival in a tropical rain forest. J. Ecol. 100, 905914. doi: 10.1111/j.1365-2745.2012.01964.x

Liu, J., Gu, Z., Shao, H., Zhou, F., and Peng, S. (2016). N-P stoichiometry in soil and leaves of Pinus massoniana forest at different stand ages in the subtropical soil erosion area of China. Environ. Earth Sci. 75, 1091. doi: 10.1007/s12665016-5888-7

Liu, S., Liao, J., Xiao, C., and Fan, X. (2016). Effects of biotic neighbors and habitat heterogeneity on tree seedling survival in a secondary mixed conifer and broad-leaved forest in Changbai Mountain. Chin. J. Plant Ecol. 40, 711-722. doi: 10.17521/cjpe.2015.0366

Lloret, F., Casanovas, C., and Peñuelas, J. (1999). Seedling survival of Mediterranean shrubland species in relation to root:shoot ratio, seed size and water and nitrogen use. Funct. Ecol. 13, 210-216. doi: 10.1046/j.13652435.1999.00309.x

Lu, R. (1999). Analytical methods of soil and agricultural chemistry (Beijing: China Agricultural Science and Technology).

Lutz, J. A., and Halpern, C. B. (2006). Tree mortality during early forest development: a long-term study of rates, causes, and consequences. Ecol. Monogr. 76, 257-275. doi: 10.1890/0012-9615(2006)076[0257:TMDEFD]2.0.CO;2

Mortimer, P. E., Le Roux, M. R., Pérez-Fernández, M. A., Benedito, V. A., Kleinert, A., Xu, J., et al. (2013). The dual symbiosis between arbuscular mycorrhiza and nitrogen fixing bacteria benefits the growth and nutrition of the woody invasive legume Acacia cyclops under nutrient limiting conditions. Plant Soil 366, 229241. doi: 10.1007/s11104-012-1421-2

Muller-Landau, H. C., Wright, S. J., Calderón, O., Condit, R., and Hubbell, S. P. (2008). Interspecific variation in primary seed dispersal in a tropical forest. J. Ecol. 96, 653-667. doi: 10.1111/j.1365-2745.2008.01399.x

Nadrowski, K., Wirth, C., and Scherer-Lorenzen, M. (2010). Is forest diversity driving ecosystem function and service? Curr. Opin. Environ. Sustain. 2, 75-79. doi: $10.1016 /$ j.cosust.2010.02.003

Nakagawa, S., and Schielzeth, H. (2013). A general and simple method for obtaining R2 from generalized linear mixed-effects models. Methods Ecol. Evol. 4, 133-142. doi: 10.1111/j.2041-210x.2012.00261.x

Niinemets, Ü. (2010). A review of light interception in plant stands from leaf to canopy in different plant functional types and in species with varying shade tolerance. Ecol. Res. 25, 693-714. doi: 10.1007/s11284-010-0712-4

Northfield, T. D., Paini, D. R., Reitz, S. R., and Funderburk, J. E. (2011). Within plant interspecific competition does not limit the highly invasive thrips, Frankliniella occidentalis in Florida. Ecol. Entomol. 36, 181-187. doi: 10.1111/ j.1365-2311.2011.01262.x

Osnas, J. L. D., Lichstein, J. W., Reich, P. B., and Pacala, S. W. (2013). Global leaf trait relationships: mass, area, and the leaf economics spectrum. Science 340, 741-744. doi: 10.1126/science.1231574

Peng, S., Schmid, B., Haase, J., and Niklaus, P. A. (2017). Leaf area increases with species richness in young experimental stands of subtropical trees. J. Plant Ecol. 10, 128-135. doi: 10.1093/jpe/rtw016

Peters, H. A. (2003). Neighbour-regulated mortality: the influence of positive and negative density dependence on tree populations in species-rich tropical forests. Ecol. Lett. 6, 757-765. doi: 10.1046/j.1461-0248.2003.00492.x 
Plath, M., Mody, K., Potvin, C., and Dorn, S. (2011). Establishment of native tropical timber trees in monoculture and mixed-species plantations: Smallscale effects on tree performance and insect herbivory. For. Ecol. Manage. 261, 741-750. doi: 10.1016/j.foreco.2010.12.004

Poorter, L., and Bongers, F. (2006). Leaf traits are good predictors of plant performance across 53 rain forest species. Ecology 87, 1733-1743. doi: 10.1890/ 0012-9658(2006)87[1733:LTAGPO]2.0.CO;2

$\mathrm{Pu}, \mathrm{X}$., Zhu, Y., and Jin, G. (2017). Effects of local biotic neighbors and habitat heterogeneity on seedling survival in a spruce-fir valley forest, northeastern China. Ecol. Evol. 7, 4582-4591. doi: 10.1002/ece3.3030

Record, S., Kobe, R. K., Vriesendorp, C. F., and Finley, A. O. (2016). Seedling survival responses to conspecific density, soil nutrients, and irradiance vary with age in a tropical forest. Ecology 97, 2406-2415. doi: 10.1002/ecy.1458

Reich, P. B. (2014). The world-wide 'fast-slow' plant economics spectrum: a traits manifesto. J. Ecol. 102, 275-301. doi: 10.1111/1365-2745.12211

Rodríguez-Calcerrada, J., Pardos, J. A., Gil, L., and Aranda, I. (2006). Acclimation to light in seedlings of Quercus petraea (Mattuschka) Liebl. and Quercus pyrenaica Willd. planted along a forest-edge gradient. Trees 21, 45-54. doi: 10.1007/s00468-006-0095-x

Rose, R., and Scott Ketchum, J. (2003). Interaction of initial seedling diameter, fertilization and weed control on Douglas-fir growth over the first four years After Planting. Ann. For. Sci. 60, 625-635. doi: 10.1051/forest:2003055

South, D. B., Harris, S. W., Barnett, J. P., Hainds, M. J., and Gjerstad, D. H. (2005). Effect of container type and seedling size on survival and early height growth of Pinus palustris seedlings in Alabama, U.S.A. For. Ecol. Manage. 204, 385-398. doi: 10.1016/j.foreco.2004.09.016

Sun, Y., Liu, H., Zhang, Y., Ma, D., and Zhao, T. (2017). Amelioration effects of dress-soil on limestone spoil at different particle sizes. Sci. Soil Water Conserv. 15, 114-122. doi: 10.16843/j.sswc.2017.03.015

Sun, Z., Huang, Y., Yang, L., Schaefer, V., and Chen, Y. (2017). Plantation age, understory vegetation, and species-specific traits of target seedlings alter the competition and facilitation role of Eucalyptus in South China. Restor. Ecol. 25, 749-758. doi: 10.1111/rec.12499

Thorpe, H. C., Astrup, R., Trowbridge, A., and Coates, K. D. (2010). Competition and tree crowns: A neighborhood analysis of three boreal tree species. For. Ecol. Manage. 259, 1586-1596. doi: 10.1016/j.foreco.2010.01.035

Uriarte, M., Canham, C. D., Thompson, J., and Zimmerman, J. K. (2004). A neighborhood analysis of tree growth and survival in a hurricane-driven tropical forest. Ecol. Monogr. 74, 591-614. doi: 10.1890/03-4031

Vaario, L.-M., Tervonen, A., Haukioja, K., Haukioja, M., Pennanen, T., and Timonen, S. (2009). The effect of nursery substrate and fertilization on the growth and ectomycorrhizal status of containerized and outplanted seedlings of Picea abies. Can. J. For. Res. 39, 64-75. doi: 10.1139/X08-156

Van de Peer, T., Verheyen, K., Baeten, L., Ponette, Q., and Muys, B. (2016). Biodiversity as insurance for sapling survival in experimental tree plantations. J. Appl. Ecol. 53, 1777-1786. doi: 10.1111/1365-2664.12721

Verheyen, K., Vanhellemont, M., Auge, H., Baeten, L., Baraloto, C., Barsoum, N., et al. (2016). Contributions of a global network of tree diversity experiments to sustainable forest plantations. Ambio 45, 29-41. doi: 10.1007/s13280-015-0685-1 von Oheimb, G., Lang, A. C., Bruelheide, H., Forrester, D.II, Wäsche, I., Yu, M., et al. (2011). Individual-tree radial growth in a subtropical broad-leaved forest: The role of local neighbourhood competition. For. Ecol. Manage. 261, 499-507. doi: 10.1016/j.foreco.2010.10.035

Wang, X., Comita, L. S., Hao, Z., Davies, S. J., Ye, J., Lin, F., et al. (2012). Localscale drivers of tree survival in a temperate forest. PloS One 7, e29469. doi: 10.1371/journal.pone.0029469

Wang, Z., Jiang, Y., Deane, D. C., He, F., Shu, W., and Liu, Y. (2019). Effects of host phylogeny, habitat and spatial proximity on host specificity and diversity of pathogenic and mycorrhizal fungi in a subtropical forest. New Phytol. 223, 462-474. doi: 10.1111/nph.15786

Weigelt, A., Schumacher, J., Walther, T., Bartelheimer, M., Steinlein, T., and Beyschlag, W. (2007). Identifying mechanisms of competition in multi-species communities. J. Ecol. 95, 53-64. doi: 10.1111/j.1365-2745.2006.01198.x

Wright, I. J., Reich, P. B., Westoby, M., Ackerly, D. D., Baruch, Z., Bongers, F., et al. (2004). The worldwide leaf economics spectrum. Nature 428, 821-827. doi: 10.1038 /nature 02403

Wright, J. S. (2002). Plant diversity in tropical forests: a review of mechanisms of species coexistence. Oecologia 130, 1-14. doi: 10.1007/s004420100809

Yang, L., Ren, H., Liu, N., and Wang, J. (2010). The shrub Rhodomyrtus tomentosa acts as a nurse plant for seedlings differing in shade tolerance in degraded land of South China. J. Veg. Sci. 21, 262-272. doi: 10.1111/j.1654-1103.2009.01140.x

Yang, X., Bauhus, J., Both, S., Fang, T., Härdtle, W., Kröber, W., et al. (2013). Establishment success in a forest biodiversity and ecosystem functioning experiment in subtropical China (BEF-China). Eur. J. For. Res. 132, 593-606. doi: 10.1007/s10342-013-0696-Z

Yang, B., Li, Y., Ding, B., Both, S., Erfmeier, A., Härdtle, W., et al. (2017). Impact of tree diversity and environmental conditions on the survival of shrub species in a forest biodiversity experiment in subtropical China. J. Plant Ecol. 10, 179189. doi: 10.1093/jpe/rtw099

Zhang, C., Li, X., Chen, Y., Zhao, J., Wan, S., Lin, Y., et al. (2016). Effects of Eucalyptus litter and roots on the establishment of native tree species in Eucalyptus plantations in South China. For. Ecol. Manage. 375, 76-83. doi: 10.1016/j.foreco.2016.05.013

Zhu, Y., Comita, L. S., Hubbell, S. P., and Ma, K. (2015). Conspecific and phylogenetic density-dependent survival differs across life stages in a tropical forest. J. Ecol. 103, 957-966. doi: 10.1111/1365-2745.12414

Conflict of Interest: The authors declare that the research was conducted in the absence of any commercial or financial relationships that could be construed as a potential conflict of interest.

Copyright (C) 2020 Shen, Li, Chen, Xi, Luo, He, Liu, Lin, Zhu, Fang, Wang, Li and Chu. This is an open-access article distributed under the terms of the Creative Commons Attribution License (CC BY). The use, distribution or reproduction in other forums is permitted, provided the original author(s) and the copyright owner(s) are credited and that the original publication in this journal is cited, in accordance with accepted academic practice. No use, distribution or reproduction is permitted which does not comply with these terms. 